\title{
Stability of Betanin as a Colorant in Pickled Turnips under different Light Exposure Conditions and with Different Additives
}

\section{Hassan S. Hajj Hussein ${ }^{1}$, Hayat Omairi ${ }^{2 a}$, Ali Al Khatib ${ }^{2 b}$, and Sami Tlais ${ }^{3, *}$}

\author{
${ }^{1}$ Biological and Chemical Department, Lebanese International University, Rayak, Lebanon. \\ ${ }^{2}$ Nutrition and Food Science Department, Lebanese International University, Bekaa $/{ }^{\mathrm{a}} /$ Beirut $^{\mathrm{b}}$, Lebanon. \\ ${ }^{3}$ Biological and Chemical Department, Lebanese International University, Bekaa/Rayak, Lebanon. \\ *Correspondence should be addressed to: Sami Tlais, Email: sami.tlais@liu.edu.lb
}

\begin{abstract}
We compared the stability of the food colorants betanin and red-beet extract in pickled turnips over a 14-week period and under different storage conditions that varied in terms of light exposure and additive content. Our findings showed that when exposed to 6 hours of sunlight or fluorescent light, on a daily basis, betanin was highly more stable than red-beet extract even when red-beet extract was stored in complete darkness. We further investigated the effect of metals and oxidation on the stability of betanin. Our results determined that EDTA and ascorbic acid significantly improved the stability of betanin colorant in pickling solution, even when exposed to direct sunlight. We tested the effect of four different concentrations of EDTA $(100,150,200$, and $250 \mathrm{mg} / \mathrm{kg})$ and three different concentrations of ascorbic acid (200, 400, and $500 \mathrm{mg} / \mathrm{kg})$ on the stability of betanin. EDTA (250 mg/kg) provided the highest improvement to betanin stability among all EDTA concentrations that were used in the study. Also, ascorbic acid $(500 \mathrm{mg} / \mathrm{kg})$ provided the highest improvement to betanin stability among the ascorbic acid concentrations that were used in the study.
\end{abstract}

Keywords-Betanin, red-beet extract, colorant stability, EDTA, ascorbic acid, light stability, and pickled turnips.

\section{INTRODUCTION}

The color of a food product is one of its most important characteristics. It confers beauty and attraction and thus consumer acceptance and preference. Consumers also rely on color to judge the quality of a food product. Color may be permanently correlated to the product's identity and become reference standards when we talk about specific shades (e.g. chocolate brown or cherry red). Different products have different reasons that necessitate the use of food colorants. The major types of food that require coloring are colorless foods, foods that lose color during processing, preparation and storage, and foods whose color is affected by seasonal and regional variations [1].

Until the nineteenth century, food colorants were all derived from natural sources such as animals, vegetables, and minerals. Nowadays these colorants are termed "Natural Colorants". The first synthetic colorant was used in 1856, and soon after, synthetic colorants gained popularity for their remarkable characteristics. Synthetic colorants are more vibrant and stable and offer a wide ISSN: 2456-1878 variety of shades in comparison with natural dyes. Some synthetic colorants are banned worldwide, others are approved by certain countries [1].

Pickled turnips are an example of a colored food product. Traditionally, slices of beetroots are used to color pickled turnips. The betanin content of the beetroots gives the pickled turnips their characteristic red color. The natural color beetroot red (betanin) is authorized for use as a food colorant and is given the E number (E162). It has long been consumed in different food products such as candies, yogurt, ice cream, salad dressing, cake mixes, powdered drinks, soft drinks, and gelatin. Red-beet extract is also used to color pickled turnips. The extract can either be a liquid concentrate (40 to $60 \%$ ) prepared by evaporation of beet juice under vacuum, or as a powdered concentrate made by spray drying. The extract typically contains between $0.4-1 \%$ betanin, $80 \%$ sugar, $9 \%$ ash, and $10 \%$ crude protein [1]. The levels of beetroot red are not of safety concerns [2]; however, betanin application in the food industry has been greatly reduced due to low stability. 
Betanin is a substituted betalamic acid, it can be converted into betaxanthins via condensation with amino acids or any available primary amine to give yellow color (fig. 1). It is proposed that betalamic acid condenses with cyclo-dopa 5O-glucoside to give betacyanins, specifically betanin, with a deep violet color [3]. There are other derivatives for betalamic acid in red-beets, betanin being the most abundant one in red-beets (40-200 $\mathrm{mg}$ of betanin/100 $\mathrm{g}$ of red-beet) [4].
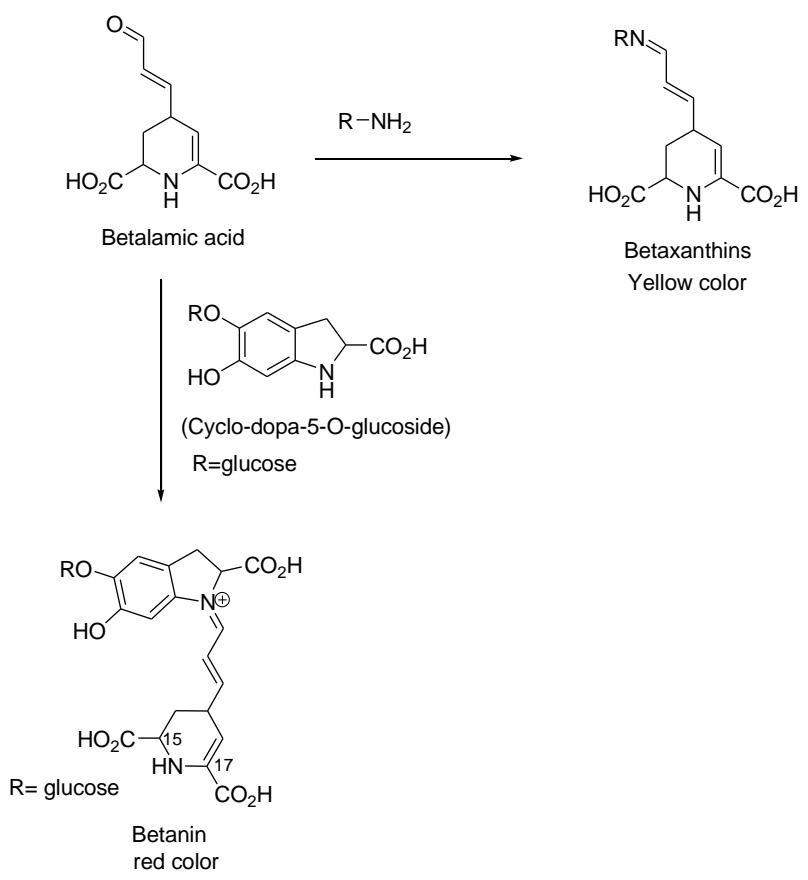

Fig.1: Betanin and betaxanthins biosynthetic pathway

The use of betanin in the food industry has decreased due to its instability. Betanin degradation is affected by different factors such as $\mathrm{pH}, \mathrm{a}_{\mathrm{w}}$ value, oxygen, antioxidants, metals, temperature, enzyme, and light [5]. The effect of $\mathrm{pH}$ on betanin has been the subject of many studies, where the optimal $\mathrm{pH}$ for betanin stability is between 4 and 6 , which is higher than the $\mathrm{pH}$ of pickling solutions. At low $\mathrm{pH}$, betanin in solution turned yellow mainly due to decarboxylation to produce dehydrobetanin. Under fluorescent light, degradation of betanin was observed at a rate that was three folds higher at $\mathrm{pH} 3$ than at pH 5 [6].

Betanin undergoes reactions with molecular oxygen; its stability can be improved by using antioxidants [6]. The addition of antioxidants such as ascorbic and isoascorbic acids favors its stability. The stability is also affected by the presence of certain metal cations such as iron, aluminum, copper, and tin which increase the degradation rate. The addition of chelating agents such as EDTA and citric acid can slow its degradation [6,7]. Temperature, an important factor in processing and storage stages of different food products, contributes to betanin degradation. This first-order degradation started by isomerization, and decarboxylation. Isomerization or decarboxylation of $\mathrm{C} 15$ does not affect betanin color, but $\mathrm{C} 17$ decarboxylation causes a hypsochromic shift resulting in an orange-red color. Enzymes can also affect betanin stability; lactic fermentation is known to promote betanin isomerization and dehydrogenation. UV or visible light absorption triggers electrons of the pigment chromophore into a high energetic state which increases reactivity and degradation rate [6].

The main challenge in the pickled turnip industry is color stability, which is an indicator of the shelf-life according to consumers. The aim of this study is to find healthy alternatives to the use of banned food colorants with pickled turnips, and to study some factors that affect the stability of betanin in pickled turnip.

\section{MATERIAL and METHODS}

\subsection{Materials}

EDTA and ascorbic acid were obtained from SigmaAldrich. Red-beet extract and betanin dye were bought from the Lebanese market. The $\mathrm{pH}$ of the solutions was measured by $\mathrm{pH}$ meter (Edge $\left.{ }^{\circledR}\right)$. The test was performed in triplicates. The sample color intensity was measured by detection on a spectrophotometer. The range of wavelengths was taken between 200 to $700 \mathrm{~nm}$. The absorbance was recorded at the maximum wavelength (535nm). Absorbance was measured on Optizen POP spectrophotometer. The turnips were bought from a local fresh market during the fall season.

\subsection{Pickling procedure}

The samples were prepared according to the most traditional methods in Lebanon. In a $3.4 \mathrm{oz}$ jar, add $20.0 \mathrm{~g}$ of turnips, and then add the preheated brine solution that is prepared by mixing 3 cups of water with one cup of vinegar $(1$ cup $=236 \mathrm{ml})$ and one tablespoon of salt $(1$ table spoon $=14 \mathrm{~g}$ ). Finally, after cooling the brine, we added $0.5 \mathrm{~g}$ of betanin or red-beet extract. The flask is then sealed well for further analysis.

\subsection{Data Analysis}

The color intensity was reported as arbitrary units based on the readings of Optizen POP spectrophotometer. Differences in color intensities for each treatment compared to the control (week 0) were assessed using oneway ANOVA and the Dunnett's multiple comparison test. Differences in color intensities for each week among 
multiple treatments were assessed using two-way ANOVA and the Tukey's multiple comparisons test.

\section{RESULTS}

We tested the stability of the colorants betanin and red-beet extracts under different conditions in pickled turnips. A total of 12 groups ( 3 jars per group) were prepared using either betanin or red-beet extract as colorant. Some groups received extra additives (e.g. EDTA or ascorbic acid) at various concentrations. In addition, some groups were stored in the dark, some were exposed to sunlight, and some were exposed to fluorescent light (Table 1). Traditional pickled turnips are prepared using beetroots as colorant. When freshly prepared, they have a vibrant dark red color that fades with time to become colorless after extended periods of storage. Commercially sold pickled turnips are displayed on supermarket shelves in transparent glass jars, which may leave them exposed to sunlight as in some observed cases or fluorescent light. First, we investigated the effect of storage lighting on the color intensity of our pickling solution over a period of 14 weeks. Pickling solutions were prepared using betanin or red-beet extract as colorant. The color intensity was tested using Optizen POP spectrophotometer, once every week, and the intensity was reported as arbitrary units of color intensity measurement.

The color intensity of betanin stored in complete darkness did not change over a period of 14 weeks (fig. 2A). The effect of room-light (fluorescent light) on betanin color intensity at week 5 was significantly lower than the control (week 0; fig. 2B). The decrease in color intensity was more pronounced at week 6 compared to the control; however, from week 7 to week 14, the decrease was very highly significant ( $\mathrm{p}$ value $=0.0007$ ) compared to the control (fig. 2B). To the unaided eye, the color became a little lighter but did not change to a different color hue and by the end of the experiment it had maintained its original color. We then tested the color intensity of betanin when stored under conditions that expose it to sunlight. When exposed to sunlight, the color intensity of betanin dropped significantly at week 5 compared to the control (fig. 2C). Further reduction in color intensity was observed at weeks 6 and 7, however, a very highly significant decrease in color intensity was observed from week 8 till week 14, compared to the control (fig. 2C). Point worth mentioning, around week 9, the pickling solution in the jars that were exposed to sunlight turned into a brownish-orange color.
Table 1. Pickling conditions in terms of colorant used, light exposure, and additive used.

\begin{tabular}{|c|c|c|c|}
\hline Group & Colorant & $\begin{array}{l}\text { Light } \\
\text { Condition }\end{array}$ & Additive \\
\hline 1 & Betanin & Darkness & None \\
\hline 2 & Betanin & $\begin{array}{l}\text { Fluorescent } \\
\text { Light }\end{array}$ & None \\
\hline 3 & Betanin & Sunlight & None \\
\hline 4 & $\begin{array}{l}\text { Red-beet } \\
\text { extract }\end{array}$ & Darkness & None \\
\hline 5 & $\begin{array}{l}\text { Red-beet } \\
\text { extract }\end{array}$ & Sunlight & None \\
\hline 6 & Betanin & Sunlight & EDTA $100 \mathrm{mg} / \mathrm{kg}$ \\
\hline 7 & Betanin & Sunlight & EDTA $150 \mathrm{mg} / \mathrm{kg}$ \\
\hline 8 & Betanin & Sunlight & EDTA $200 \mathrm{mg} / \mathrm{kg}$ \\
\hline 9 & Betanin & Sunlight & EDTA $250 \mathrm{mg} / \mathrm{kg}$ \\
\hline 10 & Betanin & Sunlight & $\begin{array}{l}\text { Ascorbic Acid } \\
200 \mathrm{mg} / \mathrm{kg}\end{array}$ \\
\hline 11 & Betanin & Sunlight & $\begin{array}{l}\text { Ascorbic } \\
400 \mathrm{mg} / \mathrm{kg}\end{array}$ \\
\hline 12 & Betanin & Sunlight & $\begin{array}{l}\text { Ascorbic Acid } \\
500 \mathrm{mg} / \mathrm{kg}\end{array}$ \\
\hline
\end{tabular}

Note: the exposure to sunlight was between the months of March and June and the exposure time was 6 hours per day. The exposure to fluorescent light was fixed at 6 hours per day. The jars that were kept under dark conditions were wrapped in aluminum foil paper and kept inside a cabinet.

On the other hand, red-beet extract did not fare so well. Under dark storage conditions, the color intensity of redbeet extract dropped very significantly ( $p$ value $=<0.0001$ ) at week 3 and continued in a steep decline all the way to week 14 (fig. 2D); the solution became colorless around week 9. However, the case was worse for red-beet extract under sunlight exposure where a significant decrease in the color intensity was first detected at week 2 (fig. 2E) and continued in a very steep decline to week 5 before it started to level off at the bottom of the spectrum until the end of the 14-week period (fig. 2E). In addition, the solution in the jars that were exposed to sunlight turned colorless around week 4. 

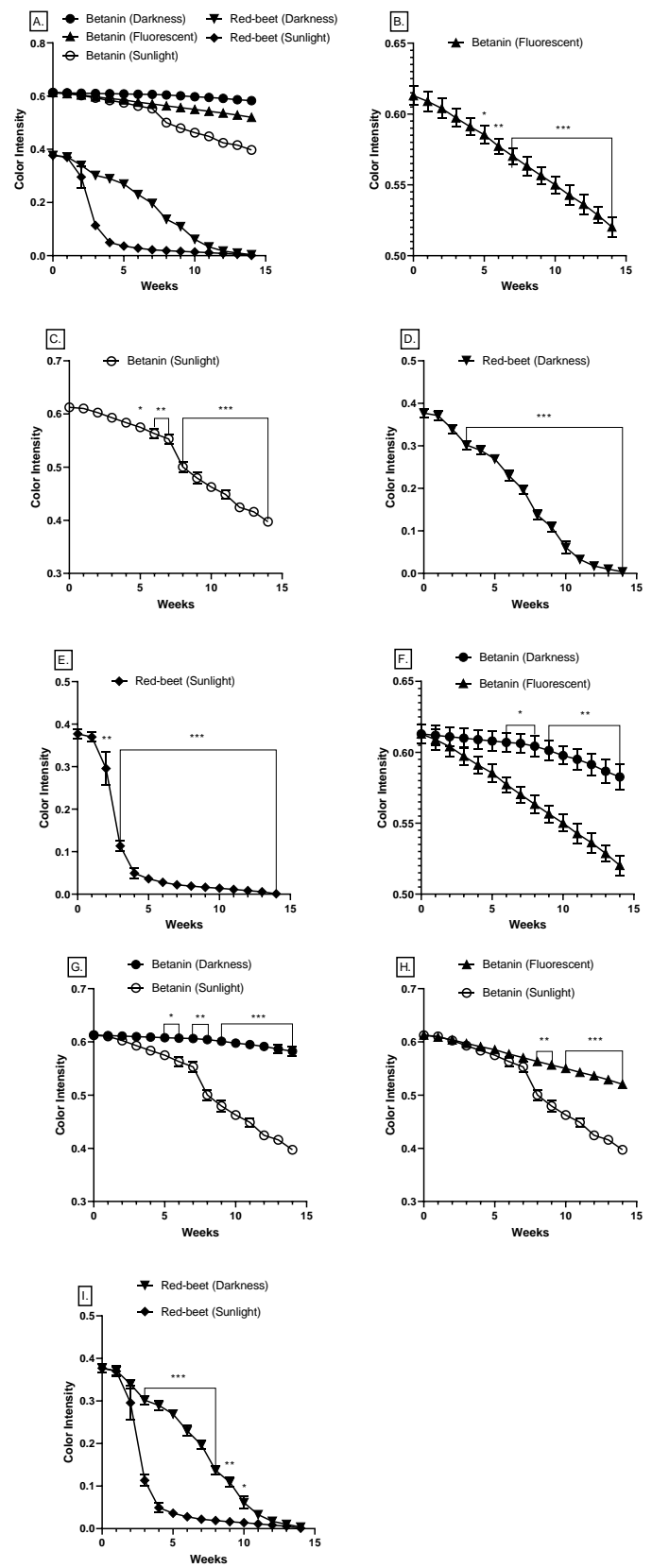

Fig.2: The effect of light exposure on the color intensity of betanin and red-beet extract colorant in pickled turnip.

Comparing the color intensity of betanin across columns (different treatments at the same period of time), a significant reduction in color intensity was detected starting at week 5 and lasting to week 14 in the jars stored under fluorescent light compared with those stored in darkness (fig. 2F). Similarly, a significant reduction in color intensity was reported at week 5 stretching to week 14 in the jars that were exposed to sunlight compared to those stored in darkness (fig. 2G). However, when comparing fluorescent vs. sunlight, the color intensity of the jars stored under sunlight were significantly lower than those stored under fluorescent light starting at week 8 and continuing to week 14 (fig. $2 \mathrm{H}$ ). In the case of the red-beet extract, the color intensity of the jars that were exposed to sunlight was significantly lower than that of the jars that were stored in darkness. The first significant difference between both groups was detected at week 3 and lasted all the way to week 10 (fig. 2I). However, between weeks 11 and 14 the color of the red-beet extract had deteriorated to the point that the solution became colorless for both groups (dark and sunlight) and no difference could be detected between the color intensities of both groups (fig. 2I).

Since betanin was found to be highly more stable than redbeet extract under dark and sunlight storage conditions, we investigated how to further increase the stability of betanin in the pickling solution exposed to sunlight to mimic the worst condition possible that the pickles could be exposed to on supermarket shelves.

First, we used EDTA to investigate the effect of metal ions on the stability of betanin under sunlight exposure conditions (fig. 3A). Four different concentrations of EDTA $(100,150,200$, and $250 \mathrm{mg} / \mathrm{kg}$ ) were studied. The results showed a drop in color intensity at week 5 due to sunlight exposure without any additives (fig. 2C); however, when coupled with EDTA $(100 \mathrm{mg} / \mathrm{kg})$, color intensity decreased significantly at weeks 2,3 , and 4 compared to the starting color intensity at week 0 (fig. 3B); however this decrease was insignificant when compared to the effect of sunlight exposure alone on the color intensity at the same weeks of the experiment (fig. 3F). Initially, adding EDTA at $100 \mathrm{mg} / \mathrm{kg}$ had no effect on the deterioration in betanin color intensity caused by sunlight exposure for the first 11 weeks of the experiment; however, at week 12, we detected a significant improvement on the stability of the color that lasted till week 14 (fig. 3F). Very similar results were detected when EDTA was used at $150 \mathrm{mg} / \mathrm{kg}$ coupled with sunlight exposure. The initial drop in color intensity was detected at week 3 and continued till week 14 (fig. 3C); however, it significantly improved the stability of betanin colorant at week 12 when compared with sunlight exposure and no additives. The color stability provided by EDTA (150 mg/kg) lasted till week 14 (fig. 3G). At 200 $\mathrm{mg} / \mathrm{kg}$ EDTA, the color intensity of betanin dropped significantly under sunlight exposure at week 3 and continued to drop gradually all through the 14-week term of the experiment (fig. 3D). When compared to sunlight exposure alone, EDTA (200 mg/kg) provided increased stability to betanin that was significantly detectable at week 10, and that lasted till week 14 (fig. $3 \mathrm{H}$ ).

When treating the pickling solution with $250 \mathrm{mg} / \mathrm{kg}$ of EDTA, a significant deterioration in the color intensity was detected at week 5 (fig. 3E), around the same time it was detected when exposed to sunlight alone without any 
additives (fig. 2C). However, when we compared EDTA (250 $\mathrm{mg} / \mathrm{kg}$ ) to sunlight (no additives) we found that EDTA significantly improved betanin color stability starting at week 8 and continued on strongly till week 14 (fig. 3I).

When comparing the effect of all four EDTA treatments, among each other, on the stability of betanin, we did not detect any significant difference between the 100, 150, and $200 \mathrm{mg} / \mathrm{kg}$ treatments. However, EDTA $(250 \mathrm{mg} / \mathrm{kg})$ significantly differed from all three other EDTA concentrations. Compared to EDTA (100 mg/kg), a significant improvement was detected at week 6, which continued strongly till week 14 (fig. 3J); compared to EDTA $(150 \mathrm{mg} / \mathrm{kg})$, a significant improvement was detected at week 8 and lasted till week 14 (fig. 3K); and lastly, when compared to EDTA $(200 \mathrm{mg} / \mathrm{kg})$, the improvement was less pronounced and it was only detectable at week 14 (fig. 3L). It is worth mentioning that the color of the solution in all of the EDTA jars became a lighter shade of red and never turned into brownish-orange as was the case with sunlight (no additives).
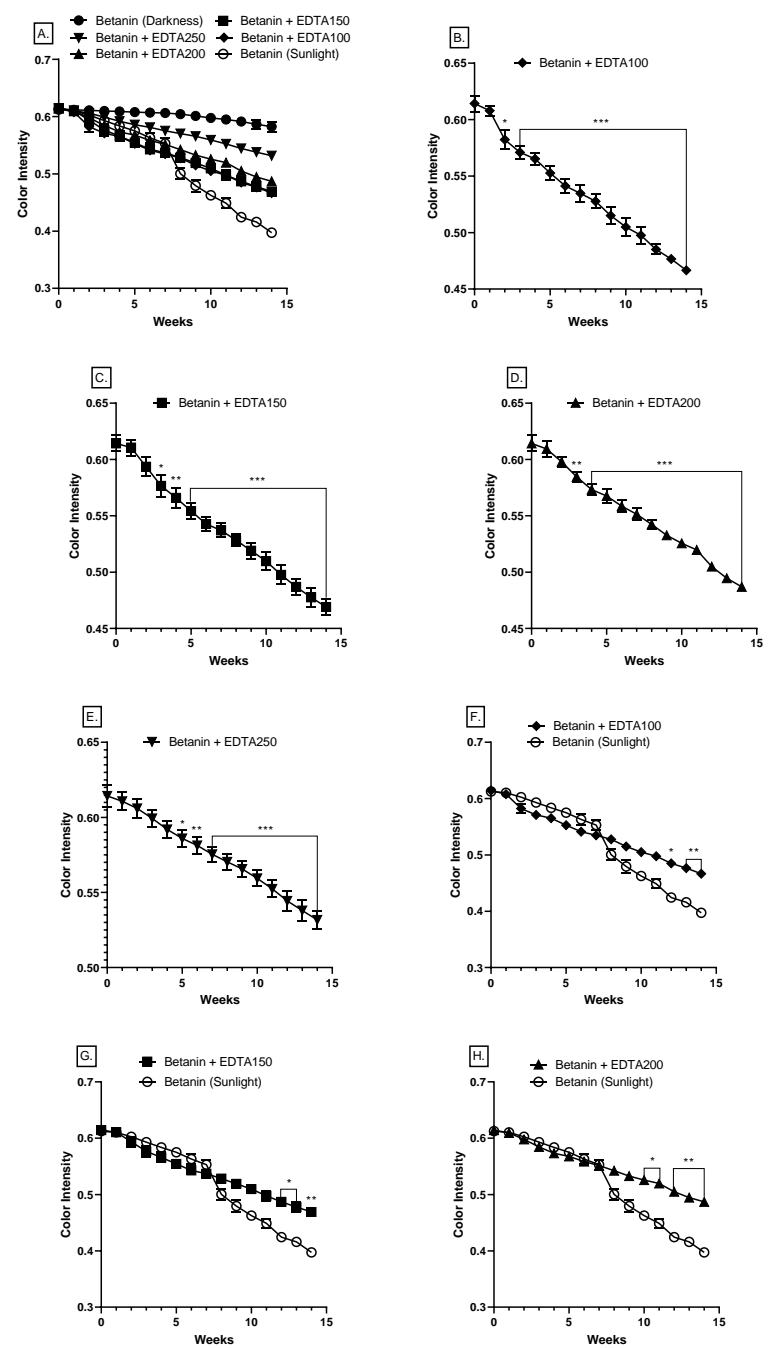
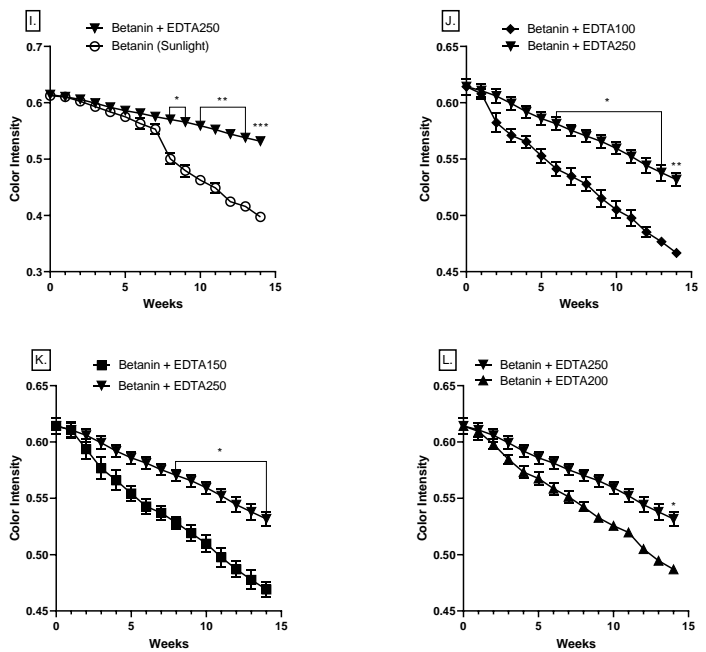

Fig.3: The effect of EDTA on the stability of betanin.

The sensitivity of betanin to oxygen has long been known and studied; so, we investigated the effect of antioxidant, ascorbic acid on the stability of betanin color in the pickling solution when exposed to sunlight (fig. 4A). According to the Codex Alimentarius, the upper limit for ascorbic acid in consumed products is $500 \mathrm{mg} / \mathrm{kg}$ (Codex Alimentarius, 1991); therefore, we investigated three different concentrations of ascorbic acid (200, 400, and $500 \mathrm{mg} / \mathrm{kg}$ ). At $200 \mathrm{mg} / \mathrm{kg}$ of ascorbic acid coupled with sunlight exposure, a significant deterioration in the color intensity of betanin was detected at week 5, which continued till week 14 (fig. 4B). However, when these jars were compared with the ones that were exposed to sunlight (no additives), a significant improvement on the stability of betanin was detected at weeks 13 and 14 (fig. 4E). Slightly different results were detected with ascorbic acid (400 $\mathrm{mg} / \mathrm{kg}$ ) when coupled with sunlight exposure. The first detectable drop in color intensity was picked up at week 4 and continued to drop at a steep angle till week 14 (fig. 4C). However, when we compared these jars with the ones that were exposed to sunlight (no additives), we detected a significant improvement in the stability of betanin at weeks 12 through 14 (fig. 4F). At $500 \mathrm{mg} / \mathrm{kg}$ ascorbic acid coupled with sunlight exposure, the first detectable deterioration in betanin color intensity was observed at week 6 and continued till week 14 (fig. 4D). However, when these jars were compared with the ones that were exposed to sunlight (no additives), a significant improvement on the stability of betanin was detected at week 8 that lasted till week 14 (fig. 4G). We then compared the difference in the effect of all three concentrations of ascorbic acid on the stability of betanin coupled with sunlight exposure. We did not detect any significant difference between the $200 \mathrm{mg} / \mathrm{kg}$ and the 400 
$\mathrm{mg} / \mathrm{kg}$ concentrations throughout the 14 weeks of the experiment (data not shown); however, ascorbic acid (500 $\mathrm{mg} / \mathrm{kg}$ ) significantly improved the stability of betanin over the $200 \mathrm{mg} / \mathrm{kg}$ concentration between weeks 12 and 14 (fig. $4 \mathrm{H}$ ), and it significantly improved the stability of betanin over the $400 \mathrm{mg} / \mathrm{kg}$ concentration between weeks 13 and 14 (fig. 4I). Also, as was the case with EDTA, adding ascorbic acid to the pickling solution prevented the color from changing to a brownish-orange color due to sunlight exposure.
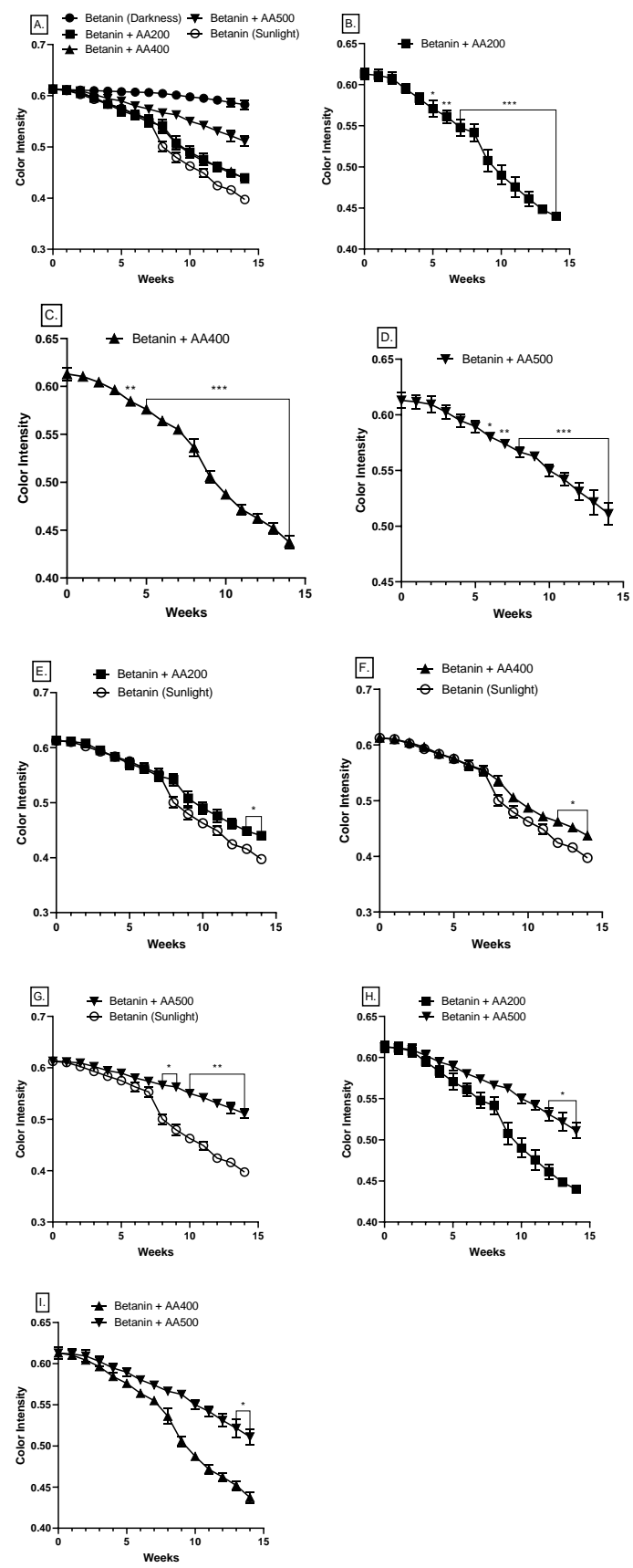

Fig.4: The effect of ascorbic acid on the stability of betanin.

\section{DISCUSSION}

The results of our study clearly showed that betanin is a more stable colorant to be used in pickling solutions than red-beet extract is. The most possible reason for the difference in the degradation rate between betanin and redbeet extract is the enzymatic factor and metals. The extraction of betanin involves a heat treatment that inactivates enzymes and thus avoiding enzymatic degradation [6]; also, in a study where beetroots were treated with HHP, the incomplete inactivation of enzymes by this process improved the quality of the beetroots in storage [8].

Both of the colorants showed better stability in the dark than when exposed to light. Betanin showed remarkable stability in the dark but it deteriorated gradually under light exposure (both fluorescent and sunlight). The comparison between samples subjected to sunlight and samples subjected to florescent light showed higher degradation in betanin in the samples that were exposed to sunlight. The difference between sunlight and fluorescent light is most likely related to the increased levels of UV and IR radiations present in sunlight. UV energizes electrons of the pigment chromophore to a more energetic state which increases reactivity and hence increases instability [6].

Different metals exist in beets [9]. The Betalain stability is affected by the presence of certain metal cations such as iron, aluminum, copper, and tin [6]. Calcium and iron cations, at levels of $100 \mathrm{ppm}$, were found to increase betanin loss [10]. In another study, copper cations negatively affected the stability of 2-decarboxy-betanin. The reaction catalyzed by $\mathrm{Cu}$ (II) ions resulted in absorption maximum shifts and generation of new absorption bands thus resulting in a decline in pigment stability [7]. The addition of chelating agents such as EDTA can solve the problem by chelating dissolved metals [6]. EDTA was added in different concentrations to the pickling solution in which betanin was used as a colorant. Based on the Lebanese Standard Institution (LIBNOR), the maximum limit for EDTA as an additive is $250 \mathrm{mg} / \mathrm{kg}$. Four concentrations of EDTA were used (100, 150, 200, and $250 \mathrm{mg} / \mathrm{kg}$ ). We found that $250 \mathrm{mg} / \mathrm{kg}$ of EDTA significantly increased the color stability of the pickling solution above what the other three lower concentrations of EDTA could provide.

The sensitivity of betanin to oxygen has long been known and studied. Betanin appeared to be unstable in the presence of oxygen. At $\mathrm{pH} \mathrm{7,} \mathrm{oxygen} \mathrm{increased} \mathrm{the} \mathrm{rate} \mathrm{of}$ betanin degradation by $15 \%$. However, in the absence of oxygen, betanin stability appeared to be greatly enhanced and the degradation occurred by a 0.5 reaction rate order 
[10]. The detrimental effect of oxygen is increased when coupled with light. Together, light and oxygen increased degradation rate by $28.6 \%$ [3]. Addition of $0.1 \%$ ascorbic acid decreased betacyanin (betalain derivative) degradation; however, the oxidation of betalains does not involve a free radical chain mechanism and thus phenolic anti-oxidants that act to inhibit free radicals are not effective [11].

Based on the above findings, we investigated the effect of ascorbic acid on the stability of betanin color in the pickling solution when exposed to sunlight. According to the Codex Alimentarius, the upper limit for ascorbic acid in consumed products is $500 \mathrm{mg} / \mathrm{kg}$ [12]; therefore, we investigated three different concentrations of ascorbic acid (200, 400, and $500 \mathrm{mg} / \mathrm{kg}$ ). We found that adding ascorbic acid to the pickling solution significantly increased the stability of betanin, with $500 \mathrm{mg} / \mathrm{kg}$ exhibiting the highest rate of improvement. The same effect was observed in a similar study where ascorbic acid at $500 \mathrm{mg} / \mathrm{kg}$ at $\mathrm{pH} 7$ increased the stability of the red beet pigments in red beet juice [13]. The red color was also stable when a mixture of ascorbic/citric acid was added to a dessert gel at temperature of $21^{\circ} \mathrm{C}$ but not at $38^{\circ} \mathrm{C}$ [14].

\section{REFERENCES}

[1] Marmion, D.M. (1991). Handbook of U.S Colorants: Food, Drugs, Cosmetics, and Medical Devices. Third Edition. Whiley Interscience Publication. ISBN: 978-0-471-50074-2

[2] EFSA Panel on Food Additives and Nutrient Sources added to food. (2015). Scientific Opinion on the re-evaluation of Beetroot red (E162) as food additive. EFSA Journal 2015; 13(12):4281

[3] Herbach, K.M., Stinzing, F.C., Carle, R. (2006). Betalain Stability and degradation- Structural and Chromatic Aspects. Journal of Food $\quad$ Science; 71:4. https://doi.org/10.1111/j.1750-3841.2006.00022.x

[4] Kapadia, G.J., Rao, G.S. (2013). Anticancer effects of red beet pigments In: Bhagyalaxmi Neelwarne, ed. Red Beet Biotechnology: Metabolites for food and pharmaceutical applications. New York, NY: Springer 2013: Ch.7.125-154.

[5] Imtyaj Khan, M. (2016). Stabilization of Betalains: A review. Food Chemistry; 197: 1280-1285. doi: 10.1111/j.1750-3841.2006.00022.x

[6] Azeredo. H. 2006. Betalains: properties, sources, applications, and stability: A review. International Journal of Food Science and Technology; 44: 2365-2376 https://doi.org/10.1111/j.1365-2621.2007.01668.x

[7] Skopinska, A,. Szot, D., Starzak, K., Wybraniec, S. (2015). Effect of $\mathrm{Cu}(\mathrm{II})$ cations on 2-Decarboxy-betanin stability in Aqueous Organic Solutions. Challenges of Modern Technology; 6:24-29.
[8] Paciulli, M., Medina-Meza, I.G., Chiavaro, E., BarbosaCanovas, G.V. (2016). Impact of Thermal and High Pressure Processing on quality parameters of beet root (Beta vulgaris.L). LWT-Food Science and Technology; 68: 98-104 https://doi.org/10.1016/j.lwt.2015.12.029

[9] Skrbic, B., Durisic-Mladenovic, N., MacVanin, N. 2009. Determination of Metal Contents in Sugar Beet (Beta vulgaris) and its products: Empirical and Chemometrical $\begin{array}{llll}\text { Approach. } & \text { Food.Sci.technol.Res., } 16 & \text { (2): 123-134 }\end{array}$ DOI: $10.3136 /$ fstr.16.123

[10] Attoe, E.L, Von Elbe, J.H. (1982). Degradation kinetics of Betanine in solutions as influenced by oxygen. Journal of Agriculture and Food Chemistry; 30: 708-712 DOI:10.1021/jf00112a021

[11] Attoe, E.L, Von Elbe, J.H. (1985). Oxygen involvement in Betanine degradation: Effect of Anti-oxidants. Journal of Food Science; 50: 106-110. https://doi.org/10.1111/j.13652621.1985.tb13287.x

[12] Joint FAO/WHO Codex Alimentarius Commission. Codex Committee on Food Additives and Contaminants. Rome: World Health Organization: Food and Agriculture Organization of the United Nations, (1991).

[13] Elbandy, M.A., Abdelfadeil M.G. (2008). Stability of Betalain Pigments from Red Beetroot (Beta vulgaris). Egyptian Journal of Food Science: 36:49-60.

[14] Driver, M.G, Francis, F.J. (1979). Stability of phytolaccanin, betanin and FD\&C red \#2 in dessert gels. Journal of Food Science; 44 (2):518-520. https://doi.org/10.1111/j.13652621.1979.tb03825.x 